\title{
A randomized, controlled study of amiodarone for prevention of atrial fibrillation after transthoracic esophagectomy
}

\author{
James E. Tisdale, PharmD, ${ }^{\mathrm{a}, \mathrm{b}}$ Heather A. Wroblewski, MSN, ${ }^{\mathrm{a}}$ Donna S. Wall, PharmD, ${ }^{\mathrm{e}}$ \\ Karen M. Rieger, MD, ${ }^{\mathrm{c}}$ Zane T. Hammoud, MD, ${ }^{\mathrm{c}}$ Jerry V. Young, MD, ${ }^{\mathrm{d}}$ and Kenneth A. Kesler, $\mathrm{MD}^{\mathrm{c}}$
}

Objective: Atrial fibrillation is common after esophagectomy. The objective of this study was to determine the efficacy and safety of amiodarone for prevention of atrial fibrillation after transthoracic esophagectomy.

\begin{abstract}
Methods: Eighty patients undergoing transthoracic esophagectomy were randomly, prospectively assigned to receive amiodarone $(n=40)$ or no prophylaxis (control group, $n=40)$. Amiodarone-treated patients received the drug by continuous infusion, initiated at the time of induction of anesthesia, at a rate of $0.73 \mathrm{mg} / \mathrm{min}(43.75 \mathrm{mg} / \mathrm{h})$, and continued for 96 hours (total dose $4200 \mathrm{mg}$ ). The primary end point was atrial fibrillation requiring treatment. Secondary end points included any atrial fibrillation lasting longer than 30 seconds and postoperative hospital and intensive care unit stays.
\end{abstract}

Results: There were no significant differences between the amiodarone and control groups in demographic characteristics, comorbid conditions, or preoperative or postoperative use of $\beta$-blockers or calcium-channel blockers. The incidence of atrial fibrillation requiring treatment was lower in the amiodarone group than in the control group $(15 \%$ vs $40 \%, P=.02$, relative risk reduction $62.5 \%)$. There were no significant differences between the amiodarone and control groups in median hospital stay (11 days vs 12 days, $P=.31$ ) or median intensive care unit stay (68 hours vs 77 hours, $p=.097$ ). There were no significant difference between the groups in the incidences of adverse effects.

Conclusions: Amiodarone prophylaxis significantly reduced the incidence of atrial fibrillation after transthoracic esophagectomy. (J Thorac Cardiovasc Surg 2010;140:45-51)

Earn CME credits at

http://cme.ctsnetjournals.org

Atrial fibrillation (AF) is a common complication after transthoracic esophagectomy, with reported incidences ranging from $13 \%$ to $46 \% .^{1-5} \mathrm{AF}$ after esophagectomy may result in a variety of adverse symptoms ${ }^{2}$ and hemodynamic instability. ${ }^{2,3,5}$ Postesophagectomy AF has been reported to prolong stay in an intensive care unit (ICU) or intermediate care unit $^{5}$ and to prolong the median total hospital stay by 5 days. $^{2}$ Strategies for prevention of AF after esophagectomy may therefore be valuable.

\footnotetext{
From the Department of Pharmacy Practice, ${ }^{a}$ School of Pharmacy \& Pharmaceutical Sciences, Purdue University, Indianapolis, Ind; the Departments of Medicine, ${ }^{\mathrm{b}}$ Surgery, ${ }^{\mathrm{c}}$ and Anesthesia, ${ }^{\mathrm{d}}$ Indiana University, School of Medicine, Indianapolis, Ind; and the Department of Pharmacy, ${ }^{\mathrm{e}}$ Indiana University Hospital of Clarian Health Partners, Indianapolis, Ind.

Supported by a grant from the Gustavus \& Louise Pfeiffer Foundation.

Disclosures: None.

Received for publication July 21, 2009; revisions received Dec 24, 2009; accepted for publication Jan 18, 2010; available ahead of print April 12, 2010.

Address for reprints: James E. Tisdale, PharmD, Department of Pharmacy Practice, School of Pharmacy \& Pharmaceutical Sciences, Purdue University, W7555 Myers Building, WHS, 1001 W 10th St, Indianapolis, IN 46202 (E-mail: jtisdale@iupui. edu).

$0022-5223 / \$ 36.00$

Copyright (c) 2010 by The American Association for Thoracic Surgery

doi:10.1016/j.jtcvs.2010.01.026
}

Amiodarone is an antiarrhythmic agent that has been shown to be effective for the management of $\mathrm{AF}$ unrelated to surgery. ${ }^{6}$ In addition, numerous prospective trials have reported that amiodarone is effective for prevention of $\mathrm{AF}$ after cardiac surgery, ${ }^{7-10}$ and evidence also supports the efficacy of amiodarone for prophylaxis against $\mathrm{AF}$ after anatomic pulmonary resection. ${ }^{11,12}$ Amiodarone has been recommended for prevention of AF after coronary artery bypass grafting by the American Heart Association, American College of Cardiology, and European Society of Cardiology (class IIa, level of evidence A). ${ }^{13}$ Despite the documented efficacy of amiodarone for prophylaxis against $\mathrm{AF}$ after coronary artery bypass grafting and pulmonary resection procedures, no prospective randomized data exist regarding its efficacy in prevention of AF after esophagectomy. The purpose of this study was to test the hypotheses that amiodarone is effective and safe in the prevention of AF after esophagectomy and that reduction in the incidence of AF would reduce the durations of postoperative hospital and ICU stays.

\section{MATERIALS AND METHODS \\ Patients}

This study was conducted at Indiana University Hospital of Clarian Health Partners, a 270-bed tertiary care hospital located in Indianapolis, Ind. All patients older than 40 years undergoing transthoracic esophagectomy through an open or minimally invasive approach were evaluated for potential enrollment. Exclusion criteria were as follows: history of AF or atrial flutter, AF or atrial flutter requiring treatment occurring during the 


\section{Abbreviations and Acronyms \\ $\mathrm{AF}=$ atrial fibrillation \\ ICU $=$ intensive care unit}

effects, and (4) cost of hospitalization from the time of surgery until discharge from the hospital. An additional end point was evaluated post hoc: the incidence of $\mathrm{AF}$ (treated or untreated) lasting longer than 30 seconds. ${ }^{13,15}$ Adverse effects were defined as follows: hypotension was a systolic blood pressure less than $90 \mathrm{~mm} \mathrm{Hg}$; bradycardia was a heart rate less than 50 beats/min; and respiratory complications were adult respiratory distress syndrome, pneumonia, pulmonary fibrosis, or atelectesis necessitating bronchoscopy or reintubation. Hospital charges were obtained from the Indiana University Hospital Claims Management Database. Hospitalderived cost:charge ratios were applied to convert hospital charges to costs.

surgical procedure, previous severe adverse reaction or contraindication to amiodarone (pulmonary fibrosis, thyroid dysfunction, hepatotoxicity), receipt of a Vaughan Williams class I or III antiarrhythmic drug or other QT interval-prolonging drug within 5 half-lives of the administration of amiodarone, pretreatment Bazett's-corrected QT (QTc) interval longer than $450 \mathrm{~ms}$, and serum alanine transaminase or aspartate transaminase concentration greater than 3 times the upper limit of normal. This study was approved by the institutional review board at Indiana University-Purdue University-Indianapolis. All patients provided written, informed consent before participation.

\section{Study Protocol}

This was a prospective, randomized, parallel-groups study. A description of patients screened, consenting, randomly assigned, and enrolled in the study is shown in Figure 1. Patients were randomly assigned to receive amiodarone (amiodarone group) or no amiodarone (control group). The specific randomization sequence was computer generated. Patients randomly allocated to the amiodarone group received a continuous intravenous infu-

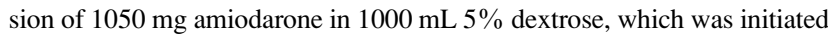
at anesthesia induction, administered at a rate of $0.73 \mathrm{mg} / \mathrm{min}(43.75 \mathrm{mg} / \mathrm{h})$, and continued for 96 hours (total dose $4200 \mathrm{mg}$ ). Patients randomly allocated to the control group did not receive amiodarone prophylaxis. Postoperative care was according to standard protocol, which included analgesia with intravenous and epidural narcotics. Continuous telemetric electrocardiographic monitoring was initiated intraoperatively. After esophagectomy, patients were admitted either to an ICU or to a non-ICU step-down unit, at the decision of the surgeon according to a standard care plan. Decisions regarding transfer of patients from the ICU to a non-ICU step-down unit and decisions regarding discharge from the hospital were made according to standard hospital criteria. Throughout the hospital course, all study patients underwent continuous monitoring with a telemetric electrocardiograph equipped with a triggered alarm and recording systems for abnormal rhythms. Any patient in whom AF developed, regardless of assignment to the amiodarone or control group, was managed by critical care attending physicians, cardiology consultants, surgical residents, or surgical attending physicians during the course of routine postoperative care with rate control or rhythm conversion strategies as deemed appropriate. All patients routinely underwent contrast esophagraphy to evaluate upper gastrointestinal integrity before resumption of oral nutrition on the 7th postoperative day or thereafter as early as the patient's condition would permit.

Blood for determination of serum amiodarone and desethylamiodarone (DEA) concentrations was collected in 10-mL nonheparinized evacuated tubes (Vacutainer; Becton, Dickinson and Company, Franklin Lakes, NJ) at 9:00 AM on postoperative day 2. The blood samples were placed on ice, allowed to clot, and then centrifuged at $2500 \mathrm{rpm}$ for 25 minutes. Serum was harvested and stored at $-70^{\circ} \mathrm{C}$ until analysis. Serum amiodarone and DEA concentrations were determined with high-performance liquid chromatography (ARUP Laboratories, Salt Lake City, Utah). ${ }^{14}$ The lower and upper limits of detection of this assay for amiodarone and DEA were $0.3 \mu \mathrm{g} / \mathrm{mL}$ and $6.0 \mu \mathrm{g} / \mathrm{mL}$, respectively.

\section{Study End Points}

The primary end point was AF requiring treatment because of a rapid ventricular rate, symptoms such as shortness of breath and fatigue, or hemodynamic compromise. ${ }^{8}$ Prespecified secondary end points were as follows: (1) total postoperative hospital stay, (2) ICU stay, (3) incidence of adverse

\section{Sample Size Determination and Data Analysis}

The a priori sample size calculation was based on an expected incidence of $\mathrm{AF}$ of $40 \%$ in the control group. ${ }^{1,5}$ The sample size of 40 patients per group allowed detection of an absolute difference in incidence of $\mathrm{AF}$ of $22.5 \%$ (corresponding to a relative risk reduction of $56 \%$ ) at a power of .80 with an $\alpha$ of .05 . Statistical analyses were performed with the statistical software SPSS 16 (SPSS Inc, Chicago, Ill). Normality of continuous data was determined with the Kolmogorov-Smirnov test. Continuous data that were normally distributed were analyzed with the Student unpaired $t$ test. Continuous data that were not normally distributed were analyzed with the nonparametric Wilcoxon rank sum test. Noncontinuous data were analyzed with the $\chi^{2}$ test or Fisher's Exact test as appropriate. Kaplan-Meier time-to-event curves were constructed, and differences between the groups were assessed with log-rank analysis. The funding source had no role in data analysis or interpretation.

\section{RESULTS}

\section{Study Population}

Between September 2004 and November 2008, a total of 80 patients were enrolled in the study, with 40 patients randomly allocated to each arm (Figure 1). There were no significant differences between experimental and control groups with respect to demographic characteristics, comorbid conditions, and preoperative or postoperative medications, including $\beta$-blockers and calcium-channel blockers (Table 1). The indication for surgery was esophageal cancer in 35 of 40 patients $(87.5 \%)$ in the amiodarone group and 37 of 40 patients $(92.5 \%)$ in the control group $(P=.71)$. The remaining patients underwent surgery for perforation and achalasia (amiodarone group 5/40 [12.5\%], control group $3 / 40[7.5 \%], P=.71)$.

Most patients (73/80, 91.3\%) underwent esophagectomy through an open transthoracic approach; the remainder $(7 / 80,8.7 \%)$ were operated on through a closed transthoracic approach (Table 1). Patients who underwent esophagectomy for malignancy also underwent en bloc periesophageal and celiac lymph node dissections. The stomach was the conduit of choice for reconstruction and was used in 77 patients in this study. Small bowel $(\mathrm{n}=1$, amiodarone group) and large bowel ( $\mathrm{n}=2$, both control group) reconstructions were performed when the stomach was not usable.

\section{Incidence of $\mathbf{A F}$}

Overall, 22 patients $(27.5 \%)$ needed treatment for development of AF. The incidence of postoperative AF was significantly lower in the amiodarone group $(6 / 40,15.0 \%)$ than in the control group $(16 / 40,40.0 \%$, relative risk 0.38 [95\% 


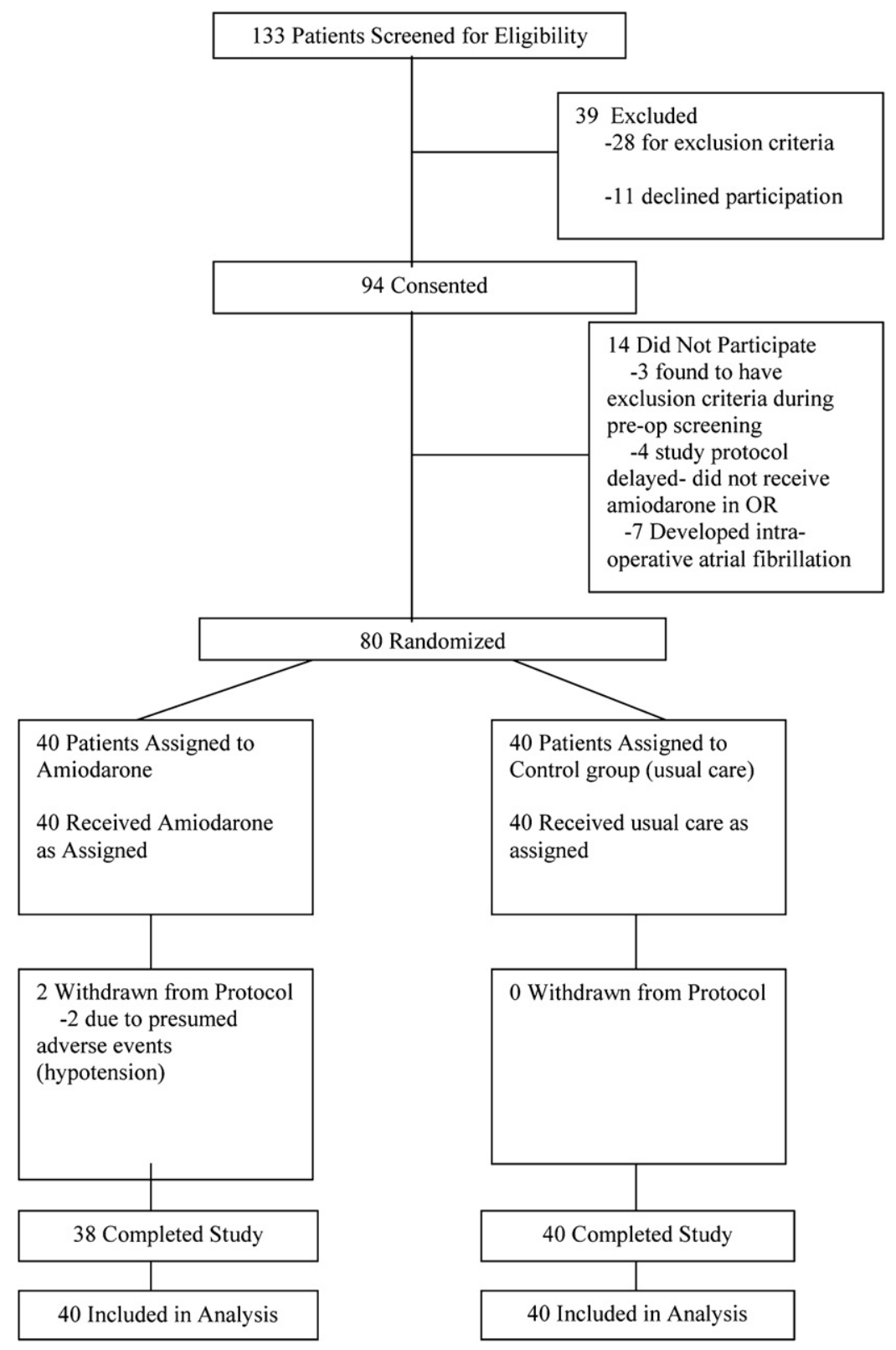

FIGURE 1. Summary of patients screened, consenting, randomized, and included in study. Pre-op, Preoperative; OR, operating room.

confidence interval $0.16-0.86], P=.02$; Figure 2), which corresponded to a $62.5 \%$ reduction in relative risk. With a $25 \%$ reduction in the absolute incidence of $\mathrm{AF}$, the number of patients needing prophylactic treatment with amiodarone to prevent 1 episode of AF would be 4.0 (95\% confidence interval 2.3-16.1). The mean maximum recorded heart rates in the patients in whom AF developed were $157 \pm 11$ and $164 \pm 14$ beats/min in the amiodarone and control groups, respectively $(P=.01)$. The mean time from surgery to the onset of electrocardiographically documented $\mathrm{AF}$ was longer in the amiodarone group than in the control group (67.5 \pm 31.3 vs $46.2 \pm 19.0$ hours), but this difference did not reach statistical significance $(P=.06)$. Of the 6 patients in the amiodarone group in whom AF developed, $2(33.3 \%)$ were discharged from the hospital in $\mathrm{AF}$, compared with 3 of 16 patients $(18.8 \%)$ in the control group $(P=.58)$.

Using the AF definition of treated or untreated lasting longer than 30 seconds, the results were identical to those obtained with the definition as $\mathrm{AF}$ requiring treatment. The incidence of postoperative AF lasting longer 30 seconds was significantly lower in the amiodarone group (6/40, $15.0 \%)$ than in the control group $(16 / 40,40.0 \%$, relative risk 0.38 [95\% confidence interval $0.16-0.86], P=.02]$, which corresponded to a $62.5 \%$ reduction in relative risk. There were no instances of AF lasting longer than $30 \mathrm{sec}-$ onds that did not require treatment. 
TABLE 1. Characteristics of patients enrolled

\begin{tabular}{|c|c|c|c|}
\hline Characteristic & $\begin{array}{c}\text { Amiodarone } \\
(\mathrm{n}=\mathbf{4 0})\end{array}$ & $\begin{array}{l}\text { Control } \\
(\mathrm{n}=\mathbf{4 0})\end{array}$ & $\begin{array}{c}P \\
\text { value } \\
\end{array}$ \\
\hline Age $(y$, mean \pm SD $)$ & $61 \pm 10$ & $63 \pm 9$ & .48 \\
\hline Male & $85.0 \%$ & $82.5 \%$ & $>.99$ \\
\hline White & $97.5 \%$ & $100 \%$ & $>.99$ \\
\hline $\begin{array}{r}\text { Preoperative weight } \\
(\mathrm{kg}, \text { mean } \pm \mathrm{SD})\end{array}$ & $86.6 \pm 13.5$ & $82.8 \pm 21.1$ & .70 \\
\hline \multicolumn{4}{|l|}{ Comorbid conditions } \\
\hline Hypertension & $52.5 \%$ & $50.0 \%$ & $>.99$ \\
\hline Heart disease* & $5.0 \%$ & $10.0 \%$ & .68 \\
\hline Diabetes mellitus & $15.0 \%$ & $10.0 \%$ & .74 \\
\hline $\begin{array}{l}\text { Chronic obstructive } \\
\text { pulmonary disease }\end{array}$ & $5.0 \%$ & $7.6 \%$ & $>.99$ \\
\hline $\begin{array}{l}\text { Preoperative chemotherapy or } \\
\text { radiation }\end{array}$ & $60.0 \%$ & $52.5 \%$ & .65 \\
\hline \multicolumn{4}{|l|}{ Preoperative medications } \\
\hline$\beta$-blockers & $25.0 \%$ & $25.0 \%$ & $>.99$ \\
\hline Calcium channel blockers $\dagger$ & $2.5 \%$ & $5.0 \%$ & $>.99$ \\
\hline Statins & $22.5 \%$ & $17.5 \%$ & .78 \\
\hline $\begin{array}{l}\text { Nonsteroidal anti- } \\
\text { inflammatory drugs }\end{array}$ & $2.5 \%$ & $10.0 \%$ & .36 \\
\hline $\begin{array}{l}\text { Angiotensin-converting } \\
\text { enzyme inhibitors }\end{array}$ & $32.5 \%$ & $25.0 \%$ & .62 \\
\hline \multicolumn{4}{|l|}{ Postoperative medications } \\
\hline$\beta$-blockers & $27.5 \%$ & $20.0 \%$ & .60 \\
\hline $\begin{array}{l}\text { Discontinuation of } \\
\text { preoperative } \beta \text { blocker }\end{array}$ & $12.5 \%$ & $20.0 \%$ & .55 \\
\hline Calcium channel blockers $\dagger$ & $2.5 \%$ & $5.0 \%$ & $>.99$ \\
\hline Statins & $15.0 \%$ & $15.0 \%$ & $>.99$ \\
\hline $\begin{array}{l}\text { Nonsteroidal anti- } \\
\text { inflammatory drugs }\end{array}$ & $2.5 \%$ & $5.0 \%$ & $>.99$ \\
\hline $\begin{array}{l}\text { Angiotensin converting- } \\
\text { enzyme inhibitors or } \\
\text { angiotensin receptor } \\
\text { blockers }\end{array}$ & $25.0 \%$ & $15.0 \%$ & .40 \\
\hline \multicolumn{4}{|l|}{ Type of surgery } \\
\hline Ivor Lewis & $42.5 \%$ & $50.0 \%$ & \\
\hline Three port & $57.5 \%$ & $50.0 \%$ & .65 \\
\hline $\begin{array}{l}\text { Video-assisted } \\
\text { thoracoscopic surgery }\end{array}$ & $10.0 \%$ & $7.5 \%$ & .71 \\
\hline \multicolumn{4}{|l|}{ Intraoperative data } \\
\hline $\begin{array}{l}\text { Estimated blood loss (mL, } \\
\text { mean } \pm \mathrm{SD})\end{array}$ & $337 \pm 143$ & $357 \pm 274$ & .71 \\
\hline $\begin{array}{l}\text { Patients receiving } \\
\text { transfusions }\end{array}$ & $20.0 \%$ & $32.5 \%$ & .31 \\
\hline $\begin{array}{l}\text { Units of blood transfused } \\
\quad(\text { mean } \pm \text { SD })\end{array}$ & $2.6 \pm 1.0$ & $2.5 \pm 1.8$ & .88 \\
\hline $\begin{array}{l}\text { Duration of surgery } \\
\qquad(\text { min, mean } \pm \mathrm{SD}) \ddagger\end{array}$ & $448 \pm 106$ & $447 \pm 85$ & .86 \\
\hline
\end{tabular}

*Heart disease includes history of myocardial infarction, coronary artery disease, and/

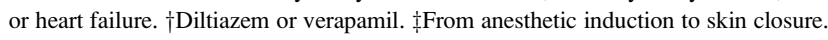

\section{Total Hospital Stay, ICU Stay, and Cost of Hospitalization}

The mean postoperative hospital and ICU stays in the overall study population were $15.2 \pm 11.2$ days (median 12 days) and $152 \pm 259$ hours (median 70 hours), respec- tively. Considering all enrolled patients, there was a trend toward a longer median total hospital stay among patients in whom AF developed than among those who did not have AF develop ( 15.0 vs 11.5 days, $P=.06$ ). There was a significant difference in median ICU stay between patients in whom AF developed and those in whom it did not (144 vs 67 hours, $P=.006$ ). Median total postsurgical hospital stays in the amiodarone and control groups were similar (11 vs 12 days, respectively, $P=.31$ ). In addition, there was no significant difference in median ICU stay between amiodaronetreated and control patients (68 vs 77 hours, $P=.097$ ). The total median cost of hospitalization in the amiodarone group was $\$ 24,153$, which was not significantly different from that in the control group $(\$ 24,977, P=.93)$.

\section{Postoperative Adverse Events, Morbidity, and Mortality}

Adverse events in both groups are presented in Table 2. There were no significant differences between amiodarone and control groups with respect to the incidences of hypotension, bradycardia, respiratory complications, or other adverse effects. Amiodarone therapy was discontinued in 2 $(5.0 \%)$ patients as a result of hypotension requiring extended vasopressor therapy.

There were a total of 2 operative deaths, both in the control group. One patient died as a result of myocardial infarction on the 11th postoperative day. The other patient died of toxic megacolon on the 13th postoperative day.

\section{Serum Amiodarone and DEA Concentrations}

Mean serum amiodarone and DEA concentrations in the treatment group on postoperative day 2 were $1.15 \pm 0.23$ $\mu \mathrm{g} / \mathrm{mL}$ and $0.032 \pm 0.095 \mu \mathrm{g} / \mathrm{mL}$, respectively. There was no significant difference in mean serum amiodarone concentration between patients in whom postoperative AF did not develop and those in whom it did $(1.23 \pm 0.37$ vs $1.07 \pm$ $0.22 \mu \mathrm{g} / \mathrm{mL}, P=.31$ ). There was no significant difference in mean serum DEA concentration between patients in whom postoperative AF did not develop and those who did have postoperative AF $(0.047 \pm 0.062 \mu \mathrm{g} / \mathrm{mL}$ vs $0.022 \pm 0.012 \mu \mathrm{g} / \mathrm{mL}, P=.34)$.

\section{DISCUSSION}

$\mathrm{AF}$ is a common complication after transthoracic esophagectomy. Mechanisms of AF development after esophagectomy are currently unknown. AF occurring after coronary artery bypass grafting may be a result of enhanced activity of the sympathetic nervous system, ${ }^{16}$ stimulation of the renin-angiotensin-aldosterone system, ${ }^{17}$ or postoperative inflammation. ${ }^{18}$ Mechanisms of AF after pulmonary resection are unclear, although some evidence suggests that elevated right heart pressure may play a significant role. ${ }^{19}$ In addition, stress-mediated enhancement of autonomic nervous system activity may contribute to AF after 


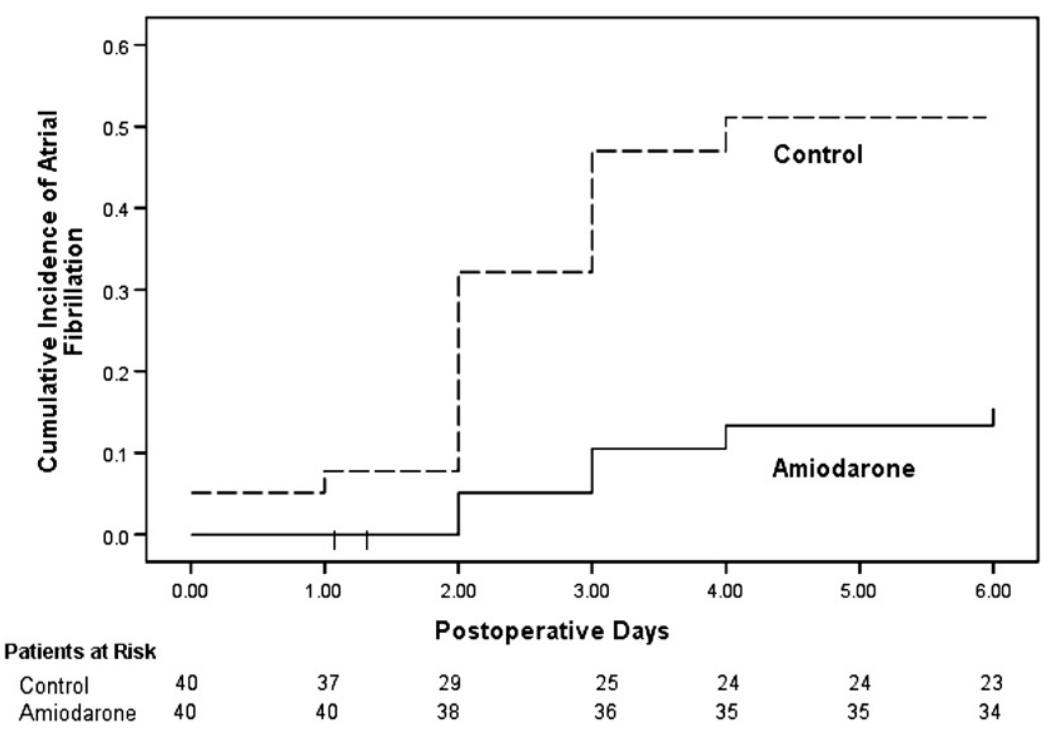

FIGURE 2. Kaplan-Meier cumulative incidence of atrial fibrillation (log-rank $P=.009)$.

pulmonary resection. ${ }^{20}$ There are conflicting data regarding the potential role of inflammation in the etiology of AF after pulmonary resection. Although mechanisms of AF after esophagectomy have not been determined, risk factors for this complication have been investigated and include age older than 65 years, male sex, history of heart disease, chronic obstructive pulmonary disease, and postoperative thoracogastric dilatation. ${ }^{21}$

Amiodarone is an antiarrhythmic agent that has been shown to be effective for the management of AF not related to surgery. ${ }^{6}$ Amiodarone inhibits sodium, potassium, and calcium conductance and possesses noncompetitive $\alpha$ - and $\beta$-blocking activity. ${ }^{6}$ The drug's antiarrhythmic effects have been primarily attributed to inhibition of sodium and potassium channels, prolonging atrial repolarization and action potential duration. Amiodarone has been widely studied for the prevention of AF after cardiac surgery ${ }^{7-10}$ and has also been shown to be effective in reducing the incidence of AF after pulmonary resection. ${ }^{11,12}$ The efficacy of amiodarone in prevention of AF after esophagectomy has not been previously studied, however; in fact, there have been no previously published studies evaluating the efficacy of any drug in the prevention of $\mathrm{AF}$ in a noncardiac thoracic surgical population consisting solely of patients undergoing esophagectomy. Bayliff and colleagues $^{22}$ did conduct a randomized, placebo-controlled evaluation of oral propranolol for prevention of arrhythmias in 99 patients undergoing noncardiac thoracic surgery, 31 of whom underwent esophagectomy. Overall, the incidence of postoperative tachyarrhythmias (including AF, atrial flutter, sinus tachycardia, supraventricular tachycardia, and ventricular tachycardia) requiring treatment was $6 \%$ in the propranolol group, compared with $20 \%$ in the placebo group $(p=.071)$. The incidence of hypotension and bradycardia, however, was significantly higher in the propranololtreated group. Among the patients who underwent

TABLE 2. Postoperative adverse events and morbidity

\begin{tabular}{|c|c|c|c|}
\hline & Amiodarone $(n=40)$ & $\operatorname{Control}(n=40)$ & $P$ value \\
\hline \multicolumn{4}{|l|}{ Cardiovascular complications } \\
\hline Hypotension* & $21(52.5 \%)$ & $19(45.0 \%)$ & .66 \\
\hline Bradycardia $\dagger$ & $2(5.0 \%)$ & $1(2.5 \%)$ & $>.99$ \\
\hline QTc interval $>500 \mathrm{~ms}$ & $1(2.5 \%)$ & $0(0 \%)$ & $>.99$ \\
\hline Ventricular tachycardia & $0(0 \%)$ & $2(5.0 \%)$ & .49 \\
\hline Respiratory complications $\ddagger$ & $9(22.5 \%)$ & $9(22.5 \%)$ & $>.99$ \\
\hline Adult respiratory distress syndrome & $0(0 \%)$ & $0(0 \%)$ & $>.99$ \\
\hline Pneumonia & $6(15.0 \%)$ & $5(12.5 \%)$ & $>.99$ \\
\hline Atelectasis & $3(7.5 \%)$ & $4(10.0 \%)$ & $>.99$ \\
\hline \multicolumn{4}{|l|}{ Other } \\
\hline Pericardial effusion & $1(2.5 \%)$ & $1(2.5 \%)$ & $>.99$ \\
\hline Anastomotic leak & $1(2.5 \%)$ & $2(5.0 \%)$ & $>.99$ \\
\hline
\end{tabular}

All data represent numbers of patients. *Systolic pressure less than $90 \mathrm{~mm} \mathrm{Hg}$. $\dagger$ Heart rate less than 50 beats/min. †ُ Respiratory complications include adult respiratory distress syndrome, pneumonia, pulmonary fibrosis, and atelectesis necessitating bronchoscopy or reintubation. 
esophagectomy, the incidence of $\mathrm{AF}$ was low $(7.1 \%$ in the placebo group vs $0 \%$ in the propranolol group).

In our prospective, randomized study, intravenous administration of amiodarone was associated with a $62.5 \%$ reduction in the relative risk of AF after esophagectomy. In addition, amiodarone prophylaxis was associated with a relatively low incidence of adverse effects. There were no significant differences between the amiodarone and control groups in the incidences of hypotension, bradycardia, respiratory adverse effects, and QTc-interval prolongation or in-hospital mortality. The reduction in the incidence of $\mathrm{AF}$ related to amiodarone prophylaxis was not, however, associated with significant reductions in median ICU stay, total hospital stay, or cost of hospitalization. In our study, the median ICU stay was significantly longer among patients in whom AF developed than among those in whom AF did not develop, independent of group assignment, and there was a nonsignificant trend toward a longer total hospital stay among patients in whom AF developed. It is possible that a reduction in the incidence of AF associated with prophylactic amiodarone might result in significant decreases in hospital stay and corresponding costs with a larger sample size or with postoperative care strategies of "fast tracking" for early hospital discharge.

The definition of $\mathrm{AF}$ used in this study was $\mathrm{AF}$ requiring treatment because of a rapid ventricular rate, symptoms such as shortness of breath and fatigue, or hemodynamic compromise. ${ }^{8}$ We chose this definition to reflect clinically important AF; we did not want to consider brief runs of AF that were asymptomatic and did not require treatment. In view of the unblinded nature of the study, however, we also performed a post hoc analysis defining $\mathrm{AF}$ as any $\mathrm{AF}$ that lasted longer than 30 seconds. ${ }^{13,15}$ When applying this more stringent definition of AF, the results of the study were identical, because no patients with $\mathrm{AF}$ of at least 30 seconds in duration were untreated. Therefore, regardless of which AF definition was used, amiodarone significantly reduced the incidence of AF among patients undergoing esophagectomy in this study.

In this investigation, amiodarone was administered by continuous intravenous infusion for a period of 96 hours. In previous studies of postoperative AF prophylaxis, amiodarone was administered orally or by nasogastric tube, ${ }^{7,9}$ or by a combination of intravenous administration followed by oral routes. ${ }^{12}$ Oral or nasogastric administration of amiodarone after esophagectomy is unfeasible for a number of reasons. After esophagectomy, some patients undergo nasogastric tube placement, with oral intake withheld for a period of approximately 7 days, whereas other patients undergo jejunostomy tube placement for immediate feeding. Previous data have indicated that serum amiodarone concentrations are substantially reduced when the drug is administered by nasogastric tube after esophagectomy. ${ }^{23}$ This may be because of poor bioavailability of amiodarone when administered into the stomach conduit or as a result of amiodarone's adherence to or adsorption by the nasogastric tube. ${ }^{24}$ Because amiodarone is absorbed in the duodenum, there are no published data regarding bioavailability of amiodarone administered through a jejunostomy tube. For these reasons, it seems prudent to avoid enteral administration of amiodarone to patients during the immediate postoperative period after esophagectomy.

Patients were excluded from our study after provision of informed consent if AF developed intraoperatively, which was an a priori exclusion criterion. These patients were excluded because the purpose of the study was to test the hypothesis that amiodarone is effective and safe in prevention of $\mathrm{AF}$ after esophagectomy, rather than during the surgical procedure itself. It is uncertain whether the mechanisms and clinical outcomes associated with intraoperative $\mathrm{AF}$ are similar to those that have been clearly documented in association with postesophagectomy $\mathrm{AF}^{25}$ In our study, 7 of 87 patients $(8.0 \%)$ who provided informed consent and were not excluded for other reasons had AF develop intraoperatively. Previous data have found the incidence of intraoperative $\mathrm{AF}$ to be as high as $17.1 \%$. The clinical significance of intraoperative $\mathrm{AF}$ and the potential benefits associated with its prevention require further study.

The incidence of AF in the control group in our study was $40 \%$. This incidence of postesophagectomy $\mathrm{AF}$ is similar to incidences reported in some previous studies $(37 \%-$ $46 \%)^{1,5}$ but substantially higher than those $(13 \%-22 \%)$ reported in other studies. ${ }^{2-4}$ Most patients in this study underwent surgery for esophageal cancer, and it has been our standard surgical approach to perform a wide en bloc mediastinal dissection from the pericardium anteriorly to the aorta posteriorly in these cases. The high incidence of $\mathrm{AF}$ in our control population could at least in part be a result of pericardial irritation related to this surgical approach. In addition, a substantial proportion of our patients also received preoperative chemotherapy and radiation, the latter of which might further predispose patients toward postoperative pericardial inflammation, potentially contributing to a relatively high incidence of AF.

Blood for determination of serum amiodarone and DEA concentrations was obtained on postoperative day 2 , which is the median time at which postoperative AF has been reported to occur. ${ }^{4}$ There was no significant difference in mean serum amiodarone or DEA concentration between those patients in whom AF developed and those in whom it did not. Further study is required to determine whether a "threshold" serum amiodarone concentration exists for optimal prevention of AF after esophagectomy.

Limitations of this investigation include the lack of a double-blind, placebo-controlled design. Although treatment of $\mathrm{AF}$ was left to the discretion of the treating physician, the thresholds for assessment of hemodynamic instability and patient symptoms were similar among the treating 
physicians and between the study groups. Additionally, although our study was adequately powered to detect significant differences in the incidence of $\mathrm{AF}$ between the amiodarone-treated and control groups, larger studies are necessary for accurate determination of differences in postoperative hospital stay and cost of hospitalization. Larger studies might also help to detect infrequently occurring adverse effects associated with amiodarone therapy. The findings of this study provide support for a large, multicenter, double-blind, placebo-controlled trial.

Prophylactic administration of intravenous amiodarone reduced the incidence of AF after transthoracic esophagectomy. Amiodarone prophylaxis against AF should be considered for this population.

We acknowledge Katy Trinkley and Neena Phadke for their assistance with data collection and Lang $\mathrm{Li}, \mathrm{PhD}$, for his review of the statistical analysis.

\section{References}

1. Konno O, Tezuka T, Muto A, Hoshino Y, Kogure M, Koyama S, et al. [Postoperative arrhythmia after operation of esophageal cancer]. Nippon Kyobu Geka Gakkai Zasshi. 1993;41:45-51. Japanese.

2. Amar D, Burt ME, Bains MS, Leung DH. Symptomatic tachydysrhythmias after esophagectomy: incidence and outcome measures. Ann Thorac Surg. 1996;61: 1506-9.

3. Murthy SC, Law S, Whooley BP, Alexandrou A, Chu K-M, Wong J. Atrial fibrillation after esophagectomy is a marker for postoperative morbidity and mortality. J Thorac Cardiovasc Surg. 2003;126:1162-7.

4. Vaporciyan AA, Correa AM, Rice DC, Roth JA, Smythe WR, Swisher SG, et al. Risk factors associated with atrial fibrillation after noncardiac thoracic surgery: analysis of 2588 patients. J Thorac Cardiovasc Surg. 2004;127:779-86.

5. Stippel DL, Taylan C, Schröder W, Beckurts KTE, Hölscher AH. Supraventricular tachyarrhythmia as early indicator of a complicated course after esophagectomy. Dis Esophagus. 2005;18:267-73.

6. Zimetbaum P. Amiodarone for atrial fibrillation. N Engl J Med. 2007;356:935-41.

7. Daoud EG, Strickberger SA, Man KC, Goyal R, Deeb GM, Bolling SF, et al. Preoperative amiodarone as prophylaxis against atrial fibrillation after heart surgery. N Engl J Med. 1997;337:1785-91.

8. Guarnieri T, Nolan S, Gottlieb SO, Dudek A, Lowry DR. Intravenous amiodarone for the prevention of atrial fibrillation after open heart surgery: the Amiodarone Reduction in Coronary Heart (ARCH) trial. J Am Coll Cardiol. 1999;34:343-7.

9. Giri S, White CM, Dunn AB, Felton K, Freeman-Bosco L, Reddy P, et al. Oral amiodarone for prevention of atrial fibrillation after open heart surgery, the Atrial Fibrillation Suppression Trial (AFIST): a randomised placebo-controlled trial. Lancet. 2001;357:830-6.

10. Mitchell LB, Exner DV, Wyse DG, Connolly CJ, Prystai GD, Bayes AJ, et al. Prophylactic Oral Amiodarone for the Prevention of Arrhythmias that Begin Early
After Revascularization, Valve Replacement, or Repair: PAPABEAR: a randomized controlled trial. JAMA. 2005;294:3093-100.

11. Lanza LA, Visbal AI, DeValeria PA, Zinsmeister AR, Diehl NN, Trastek VF. Low-dose oral amiodarone prophylaxis reduces atrial fibrillation after pulmonary resection. Ann Thorac Surg. 2003;75:223-30.

12. Tisdale JE, Wroblewski HA, Wall DS, Rieger KM, Hammoud ZT, Young JV, et al. A randomized trial evaluating amiodarone for prevention of atrial fibrillation following pulmonary resection. Ann Thorac Surg. 2009;88:886-95.

13. Fuster V, Rydén LE, Cannom DS, Crijns HJ, Curtis AB, Ellenbogen KA, et al. ACC/AHA/ESC 2006 guidelines for the management of patients with atrial fibrillation-executive summary: a report of the American College of Cardiology/ American Heart Association Task Force on Practice Guidelines and the European Society of Cardiology Committee for Practice Guidelines (Writing Committee to Revise the 2001 Guidelines for the Management of Patients With Atrial Fibrillation). Circulation. 2006;114:700-52.

14. Juenke JM, Brown PI, McMillin GA, Urry FM. A rapid procedure for the monitoring of amiodarone and desethylamiodarone by HPLC-UV detection. $J$ Anal Toxicol. 2004;28:63-6.

15. Lévy S, Camm AJ, Saksena S, Aliot E, Breithardt G, Crijns HJ, et al. International consensus on nomenclature and classification of atrial fibrillation: a collaborative project of the Working Group on Arrhythmias and the Working Group on Cardiac Pacing of the European Society of Cardiology and the North American Society of Pacing and Electrophysiology. J Cardiovasc Electrophysiol. 2003;14:443-5.

16. Kalman JM, Munawar M, Howes LG, Louis WJ, Buxton BF, Gutteridge G, et al. Atrial fibrillation after coronary artery bypass grafting is associated with sympathetic activation. Ann Thorac Surg. 1995;60:1709-15.

17. Guler N, Ozkara C, Dulger H, Kutay V, Sahin M, Erbilen E, et al. Do cardiac neuropeptides play a role in the occurrence of atrial fibrillation after coronary bypass surgery? Ann Thorac Surg. 2007;83:532-7.

18. Ucar HI, Tok M, Atalar E, Dogan OF, Oc M, Farsak B, et al. Predictive significance of plasma levels of interleukin-6 and high-sensitivity C-reactive protein in atrial fibrillation after coronary artery bypass surgery. Heart Surg Forum. 2007; 10:E131-5

19. Amar D, Roistacher N, Burt M, Reinsel RA, Ginsberg RJ, Wilson RS. Clinical and echocardiographic correlates of symptomatic tachydysrhythmias after noncardiac thoracic surgery. Chest. 1995;108:349-54.

20. Amar D, Goenka A, Zhang H, Park B, Thaler HT. Leukocytosis and increased risk of atrial fibrillation after general thoracic surgery. Ann Thorac Surg. 2006;82: $1057-61$.

21. Ma J-Y, Wang Y, Zhao Y-F, Wu Z, Liu L-X, Kou Y-L, et al. Atrial fibrillation after surgery for esophageal carcinoma; clinical and prognostic significance. World J Gastroenterol. 2006;12:449-52.

22. Bayliff CD, Massel DR, Inculet RI, Malthaner RA, Quinton SD, Powell FS, et al Propranolol for the prevention of postoperative arrhythmias in general thoracic surgery. Ann Thorac Surg. 1999;67:182-6.

23. Tisdale JE, Wroblewski HA, Hammoud ZT, Rieger KM, Young JV, Wall DS, et al. Prospective evaluation of serum amiodarone concentrations when administered via a nasogastric tube into the stomach conduit after transthoracic esophagectomy. Clin Ther. 2007;29:226-34.

24. Kotake T, Takada M, Goto T, Komamura K, Kamakura S, Morishita H. Serum amiodarone and desethylamiodarone concentrations following nasogastric versus oral administration. J Clin Pharm Ther. 2006;31:237-43.

25. Hahm T-S, Lee J-J, Yang M-K, Kim J-A. Risk factors for an intraoperative arrhythmia during esophagectomy. Yonsei Med J. 2007;48:474-9. 